\title{
Prioritas Strategi Pemasaran Biji Kopi Panggang Menggunakan Metode Analytical Hierarchy Process (AHP) Pada Lestari Coffee Roasters
}

\section{Market Strategy Priority of Roasted Coffee Beans using Analytical Hierachy Process (AHP) Method at Lestari Coffee Roasters}

\author{
Mega Anjani*, Dwi Aulia Puspitaningrum, Nanik Dara Senjawati \\ Program Studi Agribisnis Jurusan Agribisnis Fakultas Pertanian Universitas \\ Pembangunan Nasional "Veteran" Yogyakarta \\ Jl. SWK 104 (Lingkar Utara) Condong Catur Yogyakarta Indonesia 55283 \\ *Email korespondensi : megaanjani224@gmail.com
}

Diterima tanggal : 15 Desember 2020 ; Disetujui tanggal : 5 Januari 2021

\begin{abstract}
This study aims to analyze the priority of appropriate alternative strategies in the development of market share in Lestari Coffee Roasters based on marketing mix at Lestari Coffee Roasters. Basic method used to this study is descriptive analysis. Implementation method used to this study is case study. The data used are primary data and secondary data. Data collection techniques are through observation, interviews, documentations, notes, and questionnaires. The technique used to analyze are EFE (External Factor Evaluation), IFE (Internal Factor Evaluation), Matrix IE (Internal-External), and AHP (Analytical Hierarchy Process). The results of the study show that the priority in marketing mix strategy are people, place, promotion, process, physical evidence, price, and product respectively. Alternative marketing strategies that are a priority for Lestari Coffee Roasters are product development, integrations, market development, and market penetration.
\end{abstract}

Keywords : market strategy, marketing mix, AHP, priority

\begin{abstract}
ABSTRAK
Penelitian ini bertujuan untuk menganalisis prioritas alternatif strategi yang tepat dalam upaya pengembangan pangsa pasar pada Lestari Coffee Roasters berdasarkan bauran pemasaran di Lestari Coffee Roasters. Penelitian ini menggunakan metode deskriptif. Metode pelaksanaan penelitian ini menggunakan studi kasus dan metode penentuan responden menggunakan metode purposive. Macam data yang digunakan yaitu data primer dan data sekunder. Teknik pengumpulan data yaitu melalui observasi, wawancara, dokumentasi dan pencatatan, serta kuesioner. Teknik analisis yang digunakan adalah EFE (External Factor Evaluation), IFE (Internal Factor Evaluation), Matriks IE (InternalExternal), dan AHP (Analitycal Hierarchy Process). Hasil Penelitian menunjukkan bahwa faktor bauran pemasaran yang menjadi prioritas utama dalam penyusunan strategi pemasaran biji kopi panggang pada Lestari Coffee Roasters berturt-turut adalah orang, tempat, promosi, proses, sarana fisik, harga, dan produk. Alternatif
\end{abstract}


strategi pemasaran yang menjadi prioritas bagi Lestari Coffee Roasters yaitu pengembangan produk, Integrasi, pengembangan pasar, dan penetrasi pasar.

Kata kunci : strategi pemasaran, bauran pemasaran, AHP, prioritas

\section{PENDAHULUAN}

Kopi merupakan salah satu tanaman perkebunan yang penting ditinjau dari dua hal yaitu produksi dan perdagangan. Yang pertama adalah sisi produksi, tanaman ini merupakan penyokong perekonomian melalui basis produksi bahan mentah dan basis penyerapan tenaga kerja. Pada tahun 2012, produksi kopi di Indonesia mencapai 8,8\% dari total produksi dunia atau menempatkan Indoensia sebagai produsen kopi terbesar ketiga secara global setelah Brazil dan Kolombia. Kedua, kopi juga memiliki peran di sisi perdagangan. Kopi merupakan hasil pertanian yang diperdagangkan secara luas dan menjadi komoditas yang paling penting setelah minyak bumi (Zarzoso, 2003).

Sebagai negara tropis, Indonesia mempunyai potensi untuk mengembangkan industri pengolahan kopi dengan produk yang memiliki citarasa khas. Industri kopi di Indonesia termasuk salah satu industri prioritas sebagaimana ditetapkan pada Perpres No. 28 Tahun 2008 tentang Kebijakan Industri Nasional dan Roadmap Pengembangan Klastes Industri Pengolahan Kopi yang ditetapkan dalam Peraturan Menteri Perindustrian No.115/M-IND/PER/10/2009. Industri pengolahan kopi menyerap sekitar 220 ribu ton (32\%) dari total produksi kopi Indonesia dan sisanya 470 ribu ton (68\%) diekspor dalam bentuk bahan baku (Sudjarmoko, 2013).

Seiring berkembangnya budaya minum kopi di Indonesia membuat permintaan kopi dalam negeri juga meningkat. Hal tersebut menjadi indikasi adanya potensi ekonomi yang menjanjikan apabila membuka usaha pengolahan kopi di Indonesia. Salah satu industri yang bergerak pada pengolahan kopi yaitu Lestari Coffee Roasters.

Lestari Coffee Roasters merupakan salah satu industri pengolahan biji kopi panggang. Sering dengan meningkatnya pertumbuhan industri kopi, maka persaingan semakin ketat. Lestari Coffee Roasters perlu melakukan evaluasi 
Anjani, et.al., Prioritas Strategi Pemasaran Biji Kopi Panggang Menggunakan...

strategi pemasaran supaya memperoleh strategi pemasaran yang tepat untuk meningkatkan pangsa pasar. Lestari Coffee Roasters masih pada tahap pengembangan kaitannya dengan pemasaran produk, hal tersebut karena Lestari Coffee Roasters baru tiga tahun berdiri. Untuk mengetahui prioritas strategi pemasaran yang tepat berdasarkan bauran pemasaran di Lestari Coffee Roasters perlu dilakukan analisis strategi pemasaran. Pada penelitian ini bertujuan untuk menganalisis prioritas alternatif strategi yang tepat dalam upaya pengembangan pangsa pasar pada Lestari Coffee Roasters berdasarkan bauran pemasaran di Lestari Coffee Roasters.

\section{METODE PENELITIAN}

Metode dasar penelitian yang digunakan dalam penelitian ini adalah metode deskriptif. Metode deskriptif digunakan untuk melihat deskripsi, gambaran tentang Lestari Coffee Roasters, analisis faktor eksternal dan faktor internal Lestari Coffee Roasters, serta prioritas alternatif strategi pemasaran pada Lestari Coffee Roasters. Metode pelaksanaan penelitian menggunakan studi kasus. Studi kasus penelitian ini adalah fenomena yang terjadi di Lestari Coffee Roasters yang merupakan tempat usaha baru (Bogdan dan Bikien, 1982). Ciri khas Lestari Coffee Roasters yaitu merupakan satu-satunya usaha biji kopi panggang di daerah Sleman yang menggunakan kemasan berbahan dasar kertas dan tidak berlapis-lapis beserta penggunaaan cap untuk melabeli kemasan, sehingga lebih ramah lingkungan dan unik.

Metode penentuan responden penelitian menggunakan metode purposive. Pertimbangan didasarkan pada responden yang memahami dengan baik semua hal yang berkaitan dengan pemasaran pada Lestari Coffee Roasters. Data dan informasi yang diperoleh selanjutnya diolah dan dianalisis secara kuantitatif dan deskriptif (Mahfud, 2017). Adapun yang menjadi responden pada penelitian ini yaitu Chief Operational Officer (COO), Chief Financial Officer (CFO), dan Store Manager. Jenis sumber data yang digunakan pada penelitian ini yaitu data kuantitatif yang didukung data kualitatif yang diperoleh dari dalam perusahaan maupun luar perusahaan dalam bentuk data primer dan data sekunder (Umar, 2004). 
Metode pengumpulan yang digunakan pada penelitian ini yaitu berupa observasi, wawancara, dokumentasi dan pencatatan, serta kuesioner. Pengujian instrumen penelitian menggunakan uji validitas dan uji realibitas. Uji validitas dan realibitas digunakan untuk kuesioner EFE (External Factor Evaluation) dan IFE (Internal Factor Evaluation). Berdasarkan hasil uji validitas penentuan bobot dan peringkat menunjukkan nilai Corrected Item-Total Correlation atau koefisien korelasi setiap butir variabel >0,3 maka dapat disimpulkan bahwa setiap item dari variabel keusioner dinyatakan valid. Berdasarkan hasil uji realibilitas penentuan bobot dan peringkat diperoleh nilai Alpha Cronbach's eksternal sebesar 0,740 dan internal sebesar 0,737. Maka dapat disimpulkan bahwa uji realibitas kuesioner memiliki nilai realibilitas tinggi (Sugiyono, 2019).

\section{Analisis EFE (External Factor Evaluation) dan IFE (Internal Factor Evaluation)}

Matriks EFE digunakan untuk mengevaluasi faktor-faktor eksternal perusahaan. Data eksternal dikumpulkan untuk menganalisis hal-hal menyangkut persoalan ekonomi; politik dan pemerintahan; sosial, budaya, dan demografi; lingkungan; teknologi; dan persaingan. Matriks EFE (David,2011):

1. Membuat daftar faktor eksternal. Sertakan 10 sampai 20 faktor, termasuk peluang dan ancaman, yang mempengaruhi perusahaan dan industri.

2. Tetapkan setiap faktor dengan berat yang berkisar dari 0,0 (tidak penting) sampai 1,0 (sangat penting). Jumlah semua bobot ditugaskan untuk faktor harus sama yaitu 1,0. Bobot faktor merupakan hasil dari rata-rata dari hasil kuesioner yang dibagikan kepada 3 responden yang telah dipilih.

3. Peneliti menetapkan peringkat antara 1 sampai 4 untuk setiap faktor eksternal untuk menunjukkan seberapa efektif strategi perusahaan saat menanggapi faktor, di mana 4 = respon superior, 3 = respon di atas rata-rata, $2=$ respon sama dengan rata-rata, dan $1=$ respon kurang.

4. Kali nilai masing-masing faktor ini menurut peringkat untuk menentukan skor tertimbang . 
Anjani, et.al., Prioritas Strategi Pemasaran Biji Kopi Panggang Menggunakan...

5. Jumlahkan skor tertimbang untuk setiap variabel digunakan untuk menentukan total skor tertimbang untuk organisasi.

Terlepas dari jumlah peluang dan ancaman utama yang dimasukkan dalam Matriks EFE, skor bobot total tertinggi yang mungkin dicapai untuk sebuah organisasi adalah 4,0 dan skor bobot total terendah adalah 1,0. Rata-rata skor bobot total adalah 2,5. Skor bobot total sebesar 4,0 mengindikasikan bahwa sebuah organisasi merespons secara sangat baik peluang dan ancaman yang ada di industrinya (David, 2011). Matriks IFE digunakan untuk mengetahui faktor-faktor internal perusahaan yang berkaitan dengan kekuatan dan kelemahan yang dihadapi perusahaan terdiri dari aspek sumberdaya manusia, pemasaran, produksi dan operasi, keuangan, dan akuntansi serta sistem informasi (David, 2011).

Pada penelitian ini fakor-faktor internal yang diambil berdasarkan 7P bauran pemasaran yaitu produk (product), harga (price), tempat (place), promosi (promotion), orang (people), saran fisik (physical evidence), dan proses (process). Matriks IFE dapat dikembangkan dengan lima langkah berikut (David, 2011):

1. Membuat daftar faktor internal. Sertakan total 10 sampai 20 faktor internal, termasuk kelemahan.

2. Menetapkan bobot yang berkisar dari 0,0 (tidak penting) sampai 1,0 (sangat penting) untuk masing-masing faktor. Jumlah semua bobot harus sama yaitu 1,0. Penentuan bobot merupakan hasil rata-rata kuesioner yang dibagikan kepada 3 responden yang dipilih.

3. Penelitian menetapkan peringkat 1 sampai 4 pada setiap faktor untuk menunjukkan apakah faktor yang merupakan major weakness (rating=1), minor weakness (rating=4).

4. Kali masing-masing faktor untuk menentukan skor tertimbang untuk masingmasing variabel.

5. Jumlahkan skor tertimbang untuk setiap variabel untuk menentukan total skor tertimbang untuk organisasi.

Terlepas dari beberapa banyak faktor yang dimasukkan ke dalam matriks IFE, skor berkisar antara 1,0 sebagai titik terndah dn 4,0 sebagai titik tertinggi, denganskor rata-rata 2,5 mengindikasikan posisi internal yang kuat. Jumlah faktor 
tidak memengaruhi kisaran skor karena bobot selalu berjumlah 1,0 (David, 2011). Matriks IFE pada penelitian ini dibuat berdasarkan analisis internal strategis berkaitan dengan kekuatan dan kelemahan yang dianggap penting yang kemudian diberikan bobot dan rating (Affandy, 2017).

\section{Matriks IE (Internal-External)}

Matriks IE memposisikan berbagai divisi suatu organisasi dalam tampilan sembilan sel. Matriks IE digunakan pada tahap pencocokan. Mecocokan faktorfaktor keberhsailan penting eksternal dan internal merupakan kunci untuk menciptakan strategi alternatif yang masuk akal. Setelah mengidentifikasi faktorfaktor eksternal dan internal menggunakan matriks EFE (External Factor Evaluation) dan IFE (Internal Factor Evaluation), kemudian melakukan tahap pencocokan dengan matriks IE. Matriks IE didasarkan pada skor bobot IFE (sumbu $\mathrm{x}$ ) dan skor bobot EFE (sumbu y). skor bobot EFE dan IFE dapat menetukan suatu usaha terdapat pada kuadran mana. Dari sembilan kuadran terbagi menjadi tiga bagian implikasi strategi yang berbeda-beda (David, 2011).

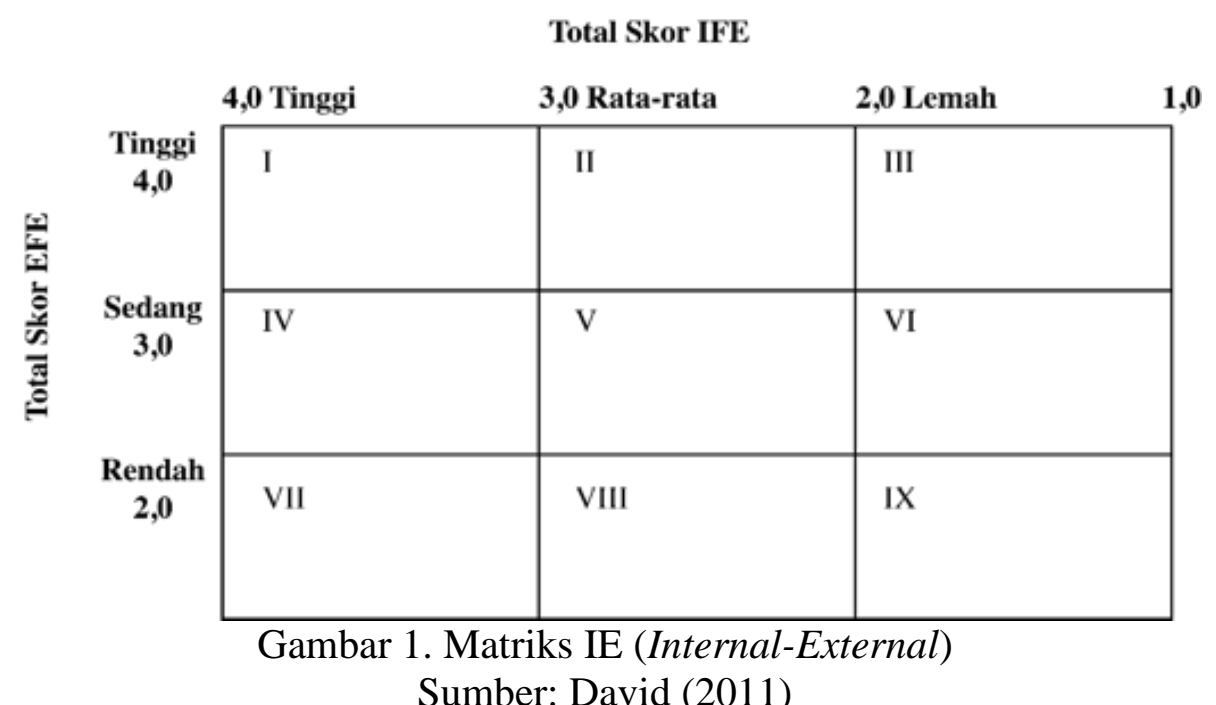

\section{AHP (Analytical Hierarchy Process)}

AHP sering digunakan sebagai metode pemecahan masalah dibanding dengan metode yang lain karena alasan-alasan sebagai berikut (Saaty, 1993): 
Anjani, et.al., Prioritas Strategi Pemasaran Biji Kopi Panggang Menggunakan...

1. Struktur yang berhirarki, sebagai konsekuensi dari kriteria yang dipilih sampai pada subkriteria yang paling dalam.

2. Memperhitungkan validitas sampai dengan batas toleransi inkonsistensi berbagai kriteria dan alternatif yang dipilih oleh pengambilan keputusan.

3. Memperhitungkan daya tahan output analisis sensitivitas pengambilan keuputusan.

Urut proses pada sistem meliputi (Walangare dkk, 2012):

1. Menentukan tujuan, kriteria, dan alternatif.

2. Menyusun kriteria-kriteria ke dalam bentuk matriks berpasangan.

3. Menjumlahkan matriks kolom.

4. Menghitung nilai elemen kolom kriteria dengan rumus masing-masing elemen kolom dibagi dengan jumlah matriks kolom.

5. Menghitung nilai prioritas kriteria dengan rumus menjumlah matriks baris hasil langkah ke-4 dan hasilnya dibagi dengan jumlah kriteria.

6. Menguji konsistensi setiap matriks berpasangan. Dengan langkah sebagai berikut:

a. Menghitung Indeks Konsistensi (CI) dengan rumus:

$$
\mathrm{CI}=\frac{\lambda \text { maksimum }-n}{n-1}
$$

Keterangan:

CI $=$ Indeks Konsistensi

$\lambda$ maksimum $=$ nilai eigen terbesar dari matriks berordo $\mathrm{n}$

$\mathrm{n} \quad=$ jumlah kriterita

Nilai eigen terbesar didapat dengan menjumlahkan hasil perkalian jumlah kolom dengan vektor prioritas.

b. Menghitung Rasio Konsistensi (CR) dengan rumus:

$$
\begin{gathered}
C R=\frac{C I}{R I} \quad \text { Dimana nilai Random Index (RI) berdasarkan perhitungan } \\
\text { Saaty, dapat dilihat dari tabel } 1 .
\end{gathered}
$$


Tabel 1. Tabel Random Index

\begin{tabular}{crrrrrrrrrr}
\hline $\mathbf{n}$ & $\mathbf{1}$ & $\mathbf{2}$ & $\mathbf{3}$ & $\mathbf{4}$ & $\mathbf{5}$ & $\mathbf{6}$ & $\mathbf{7}$ & $\mathbf{8}$ & $\mathbf{9}$ & $\mathbf{1 0}$ \\
\hline RI & 0.00 & 0.00 & 0.58 & 0.90 & 1.12 & 1.24 & 1.32 & 1.41 & 1.45 & 1.49 \\
\hline
\end{tabular}

Sumber: Walangare dkk (2012)

7. Menyusun matriks baris antara alternatif versus kriteria yang isinya hasil perhitungan proses langkah 2 sampai 5.

8. Hasil akhirnya berupa prioritas global sebagai nilai yang digunakan oleh pengambil keputusan berdasarkan skor yang tertinggi.

\section{HASIL ANALISIS DAN PEMBAHASAN}

\section{Analisis EFE (External Factor Evaluation) dan IFE (Internal Factor Evaluation)}

Matriks EFE menggambarkan faktor-faktor internal yang berpengaruh terhadap penentuan alternatif strategi di Lestari Coffee Roasters. Matriks EFE merupakan suatu analisis yang digunakan untuk mengetahui pengaruh faktor eksternal terhadap Lestari Coffee Roasters. Faktor yang menjadi peluang utama dan ancaman utama Lestari Coffee Roasters dapat diketahui melalui matriks EFE.

Tabel 2. Matriks EFE (External Factor Evaluation) Lestari Coffee Roasters 2020

\begin{tabular}{lccc}
\hline \multicolumn{1}{c}{ Faktor Eksternal } & Bobot & Rating & Skor \\
\hline Peluang & & & \\
\hline Penggunaan sosial media yang aktif & 0,116 & 3,3 & 0,386 \\
Relasi yang luas & 0,116 & 3,7 & 0,425 \\
Semakin banyaknya kedai kopi di Yogyakarta & 0,084 & 3,3 & 0,281 \\
Semakin banyaknya pecinta kopi & 0,105 & 3,3 & 0,351 \\
Sering adanya pameran kopi & 0,105 & 3,3 & 0,351 \\
Selalu tersedianya bahan baku & 0,116 & 3,3 & 0,386 \\
\hline Jumlah & 0,642 & 20,3 & 2,179 \\
\hline Ancaman & & & \\
\hline Penjualan tidak stabil & 0,105 & 2,3 & 0,246 \\
Pengaruh cuaca dan musim & 0,084 & 2,7 & 0,225 \\
Kualitas bahan baku yang tidak sustainable & 0,084 & 1,3 & 0,112 \\
Usaha lain dengan produk sejenis & 0,084 & 2,3 & 0,196 \\
\hline Jumlah & 0,358 & 8,7 & 0,779 \\
\hline Total & 1 & 29 & 2,958 \\
\hline
\end{tabular}

Sumber: Analisis Data Primer, 2020 
Anjani, et.al., Prioritas Strategi Pemasaran Biji Kopi Panggang Menggunakan...

Peluang utama Lestari Coffee Roasters adalah relasi yang luas dengan skor sebesar 0,425. Sedangkan ancaman utama Lestari Coffee Roasters adalah penjualan tidak stabil (jumlah konsumen yang fluktuatif) dengan skor sebesar 0,246. Skor total matriks EFE adalah 2,958 yang memiliki arti bahwa Lestari Coffee Roasters dalam menghadapi dinamika lingkungan eksternal posisi usaha relatif kuat (David, 2011). Dengan kata lain Lestari Coffee Roasters dapat mengatasi ancaman dengan memanfaatkan peluang (Amelinda dan Charly, 2017).

Matriks IFE menggambarkan faktor-faktor internal yang berpengaruh terhadap penentuan alternatif strategi di Lestari Coffee Roasters. Matriks IFE merupakan suatu analisis yang digunakan untuk mengetahui faktor internal terhadap Lestari Coffee Roasters. Kekuatan utama dan kelemahan utama Lestari Coffee Roasters dapat diketahui berdasarkan Matriks IFE.

Tabel 3. Matriks IFE (Internal Factor Evaluation) Lestari Coffee Roasters

\begin{tabular}{lrrr}
\hline \multicolumn{1}{c}{ Faktor Internal } & Bobot & Rating & \multicolumn{1}{c}{ Skor } \\
\hline Kekuatan & & & \\
\hline Variasi jenis kopi & 0,095 & 3,7 & 0,348 \\
Sortasi bahan baku dengan tenaga kerja manusia & 0,069 & 3,3 & 0,230 \\
Kemasan yang ramah lingkungan & 0,086 & 3,3 & 0,287 \\
Budaya antar karyawan & 0,095 & 3,3 & 0,316 \\
Bahan baku berkualitas & 0,095 & 3,3 & 0,316 \\
Kualitas produk baik & 0,095 & 3,7 & 0,348 \\
Lokasi strategis & 0,086 & 3,3 & 0,287 \\
Pelayanan yang ramah & 0,086 & 3,7 & 0,316 \\
Ruangan yang bersih & 0,095 & 3,3 & 0,316 \\
\hline Jumlah & 0,802 & 31,0 & 2,764 \\
\hline Kelemahan & & & \\
\hline Kapasitas mesin roasting yang kecil & 0,060 & 2,7 & 0,162 \\
Luas kantor yang kurang luas & 0,069 & 2,3 & 0,159 \\
Jumlah sumberdaya manusia yang terbatas & 0,069 & 2,3 & 0,159 \\
\hline Jumlah & 0,198 & 7,3 & 0,480 \\
\hline Total & 1 & 38,3 & 3,244 \\
\hline Sumber: Analisi Data Primer 2020 & &
\end{tabular}

Sumber: Analisis Data Primer, 2020

Kekuatan utama Lestari Coffee Roasters adalah variasi jenis kopi dan kualitas produk baik dengan skor sebesar 0,348. Sedangkan kelemahan utama Lestari Coffee Roasters adalah kapasitas mesin roasting yang masih kecil dengan skor sebesar 0,162. Skor total matriks IFE adalah 3,244 yang memiliki arti bahwa Lestari 
Coffee Roasters dalam menghadapi dinamika lingkungan internal posisi usaha relatif kuat (David, 2011). Dengan kata lain Lestari Coffee Roasters dapay mengatasi kelemahan dengan memanfaatkan kekuatan (Amelinda dan Charly, 2017).

\section{Analisis Matriks IE (Internal-External)}

Penyusunan matriks IE dengan mengkombinasikan nilai yang diperoleh pada matriks EFE dan IFE. Matriks IE adalah matriks yang akan memformulasikan nilai matriks IFE dan matriks EFE untuk menunjukkan posisi Lestari Coffee Roasters saat ini (Effendi, 2017). Berdasarkan matriks EFE total skor sebesar 2,958 dan total skor pada matriks IFE yaitu sebesar 3,244. Nilai rata-rata IFE dan EFE diperoleh dari jumlah dari skor pada masing-masing faktor, di mana skor tersebut didapatkan dari perkalian antara rata-rata rating dan rata-rata bobot pada masing-masing faktor (Setyorini, 2016).

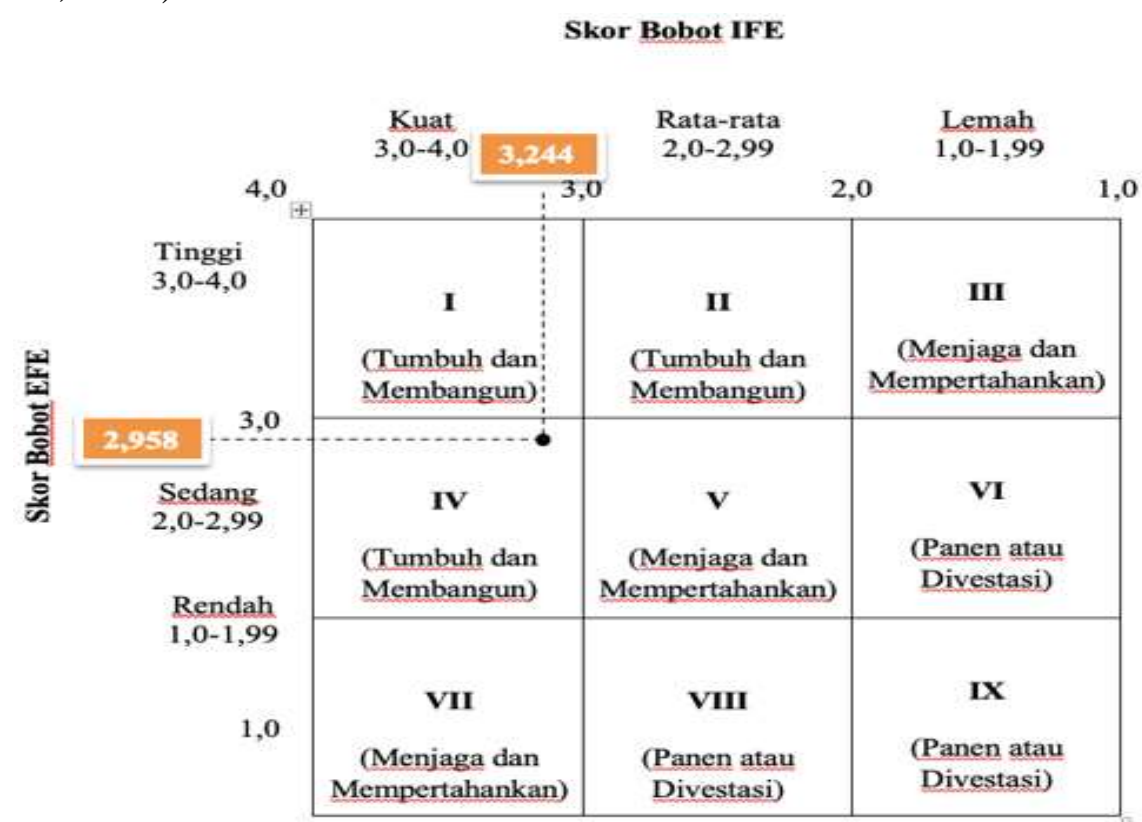

Gambar 2. Matriks IE (Internal-External)

Sumber: Analisis Data Primer 2020

Hasil dari matriks IE yang menghubungkan skor total EFE dan IFE menunjukkan posisi Lestari Coffee Roasters pada sel IV yang memiliki arti bahwa usaha Lestari Coffee Roasters berada pada Tumbuh dan Membangun. Strategi yang disarankan yaitu penetrasi pasar, pengembangan produk, pengembangan pasar, dan 
Anjani, et.al., Prioritas Strategi Pemasaran Biji Kopi Panggang Menggunakan...

integrasi (integrasi ke belakang, ke depan, dan integrasi horizontal). Pada sel IV menunjukkan bahwa faktor internal Lestari Coffee Roasters lebih tinggi daripada faktor eksternal.

\section{Analytic Hierarchy Process (AHP)}

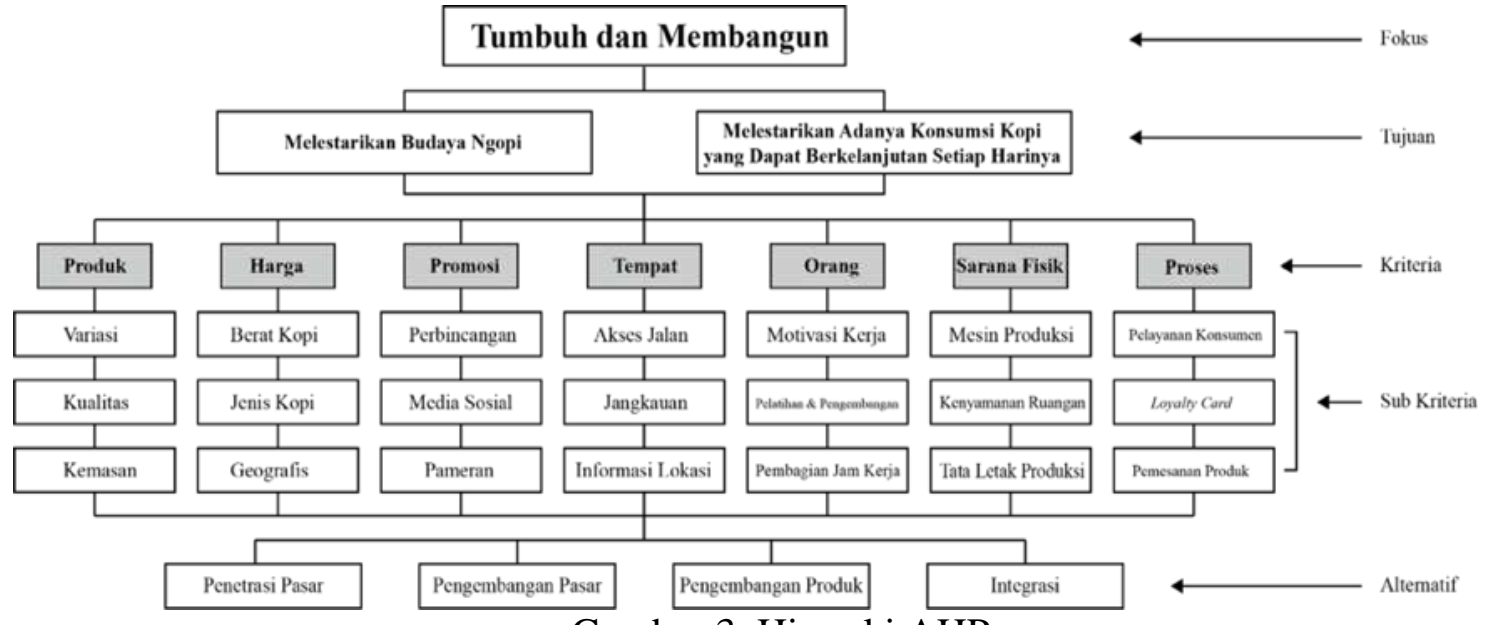

Gambar 3. Hierarki AHP

Sumber: Analisis Data Primer 2020

Fokus yang diambil berdasarkan posisi usaha yang diperoleh pada Matriks

IE (Internal-External) yaitu posisi usaha tumbuh dan berkembang. Tujuan yang diambil berdasarkan tujuan Lestari Coffee Roasters. Kriteria yang diambil berdasarkan bauran pemasaran 7P (product, price, promotion, place, physical evidence, people, process). Sub kriteria yang diambil berdasarkan keadaan dilapangan dengan didasari bauran pemasaran 7P. Kemudian, alternatif strategi yang tawarkan berdasarkan alternatif strategi pada posisi usaha Tumbuh dan Membangun.

1. Prioritas Visi Lestari Coffee Roasters Berdasarkan Fokus Posisi Usaha Tumbuh dan Membangun

Tabel 4. Bobot dan Prioritas Visi Pemasaran Kopi pada Lestari Coffee Roasters 2020

\begin{tabular}{lrrr}
\hline \multicolumn{1}{c}{ Visi } & Bobot & Prioritas & \multicolumn{1}{c}{ IR } \\
\hline Melestarikan Budaya Ngopi & 0,631 & 1 & 0,00 \\
Memastikan Adanya Konsumsi Kopi Yang Dapat & 0,369 & 2 & \\
Berkelanjutan Setiap Harinya & & &
\end{tabular}

Sumber: Analisis Data Primer, 2020 
Tujuan yang menjadi prioritas pertama Lestari Coffee Roasters yaitu Melestarikan Budaya Ngopi. Visi melestarikan budaya ngopi menjadi prioritas utama secara keseluruhan dalam kegiatan pemasaran dengan bobot sebesar 0,631. Visi ini menempati prioritas utama karena supaya budaya minum kopi di Indoensia yang sudah tercipta sejak nenek moyang tidak hilang. Selain itu, supaya masyarakat Indonesia juga ikut serta menikmati hasil produksi kopi di dalam negeri. Penjualan kopi lokal di Indonesia berawal dari kurangnya tingkat konsumsi kopi lokal di Indonesia dan sebagai upaya untuk memenuhi kebutuhan masyarakat pecinta kopi supaya tidak kesulitan dalam mendapatkan kopi lokal. Selain itu, Lestari Coffee Roasters juga ingin mengenalkan kopi lokal kepada masyarakat supaya masyarakat lebih mengenal kopi lokal yang memiliki kualitas yang tidak kalah baik dibanding kopi impor dan kopi lokal di Indonesia semakin diminati.

2. Prioritas Bauran Berdasarkan Visi Melestarikan Budaya Ngopi

Bauran yang menjadi prioritas pertama dengan visi melestarikan budaya ngopi yaitu bauran orang (people) dengan bobot sebesar 0,206. Hal tersebut karena Lestari Coffee Roasters selalu berusaha membangun komunikasi yang baik antar orang di dalamnya. Selain itu, untuk melestarikan budaya ngopi sangat diperlukan kemampuan dan pengetahuan di bidang kopi. Apabila kualitas sumberdaya manusianya memiliki pengalaman dan kemampuan yang mumpuni di bidang kopi maka akan lebih mudah melestarikan budaya ngopi dengan menyebarkan informasi kopi lokal kepada masyarakat.

Tabel 5. Bobot dan Prioritas Bauran Berdasarkan Visi Melestarikan Budaya Ngopi pada Lestari Coffee Roasters

\begin{tabular}{lrr}
\hline \multicolumn{1}{c}{ Bauran Pemasaran } & \multicolumn{1}{r}{ Bobot } & Prioritas \\
\hline Produk (Product) & 0,076 & 7 \\
Harga (Price) & 0,092 & 6 \\
Promosi (Promotion) & 0,164 & 3 \\
Tempat (Place) & 0,172 & 2 \\
Orang (People) & 0,206 & 1 \\
Sarana Fisik (Physical Evidence) & 0,133 & 5 \\
Proses (Process) & 0,156 & 4 \\
\hline Total & 1 & \\
\hline IR (Inconcistency Ratio) & 0,04 & \\
\hline
\end{tabular}

Sumber: Analisis Data Primer, 2020 
Anjani, et.al., Prioritas Strategi Pemasaran Biji Kopi Panggang Menggunakan...

3. Prioritas Dimensi Bauran Orang Berdasarkan Visi Melestarikan Budaya Ngopi

Dimensi yang menjadi prioritas pertama yaitu pelatihan dan pengembangan terhadap sumberdaya manusia di Lestari Coffee Roasters dengan bobot sebesar 0,456. Hal tersebut karena tujuan melestarikan budaya ngopi sangat perlu keterampilan dan pengetahuan mengenai kopi. Sehingga modal dasar Lestari Coffee Roasters dalam melestarikan budaya ngopi pada bauran orang yaitu memprioritaskan pelatihan dan pengembangan. Dengan begitu sumberdaya manusia di Lestari Coffee Roasters menjadi semakin bagus.

Tabel 6. Dimensi Bauran Orang Berdasarkan Visi Melestarikan Budaya Ngopi pada Lestari Coffee Roasters 2020.

\begin{tabular}{llll}
\hline \multirow{4}{*}{ Bauran Orang } & \multicolumn{1}{c}{ Dimensi } & \multicolumn{1}{c}{ Bobot } & \multicolumn{1}{c}{ IR } \\
\cline { 2 - 3 } & Motivasi Kerja & 0,357 & 0,01 \\
\cline { 2 - 3 } & Pelatihan \& Pengembangan & 0,456 & \\
\cline { 2 - 3 } & Pembagian Jam Kerja & 0,187 & \\
\hline
\end{tabular}

Sumber: Analisis Data Primer, 2020

4. Alternatif Strategi yang Tepat untuk Disarankan Kepada Lestari Coffee Roasters berdasarkan prioritas

Berdasarkan prioritas tujuan usaha Lestari Coffee Roasters dan prioritas bauran pemasaran, alternatif strategi yang menjadi prioritas yaitu strategi pengembangan produk. Hal tersebut sesuai dengan penelitian yang dilakukan Hasbi (2018) mengenai metode AHP yaitu alat untuk menentukan strategi mana yang harus diprioritaskan oleh Lestari Coffee Roasters untuk meningkatkan penjualan biji kopi panggang. Selain itu, strategi pemasaran melalui penentuan prioritas adalah perusahaan harus menjaga produksinya agar dapat selalu menyediakan produknya setiap saat kosumen meminta (Nurhasanah, 2006). Hal tersebut sesuai dengan peluang Lestari Coffee Roasters yaitu semakin banyaknya kedai kopi di Yogyakarta dan semakin banyaknya pecinta kopi. Meningkatnya masyarakat dalam mengonsumsi kopi dapat menjadi peluang bagi Lestari Coffee Roasters untuk menjalankan strategi pengembangan produk. 
Jurnal Dinamika Sosial Ekonomi, 22 (1) : 17-32

Tabel 7. Prioritas Alternatif Strategi Yang Disarankan Kepada Lestari Coffee

\begin{tabular}{llcr}
\hline & \multicolumn{1}{c}{ Alternatif Strategi } & Bobot & \multicolumn{1}{c}{ IR } \\
\cline { 2 - 4 } Pelatihan \& & Penetrasi Pasar & 0,189 & \\
Pengembangan & Pengembangan Pasar & 0,236 & \multirow{2}{*}{0,01} \\
& Pengembangan Produk & 0,296 & \\
& Integrasi & 0,279 & \\
\hline
\end{tabular}

Sumber: Analisis Data Primer, 2020

Ada tiga macam strategi pengembangan produk (Kotler,1987) yaitu strategi peningkatan kualitas, strategi peningkatan keistimewaan, dan strategi peningkatan gaya. Peningkatan kualitas produk dapat dilakukan dengan pelatihan dan pengembangan. Karena apabila sumberdaya manusia pada Lestari Coffee Roasters memiliki kemampuan dan keterampilan yang baik maka produk yang dihasilkan juga akan berkualitas baik. Teknis yang dapat dilakukan yaitu dengan menciptakan produk siap minum, sehingga membuat praktis konsumen. Pada peningkatan keistimewaan produk Lestari Coffee Roasters telah menerapkan strategi tersebut yaitu dengan mencantumkan information card sesuai dengan daerah asal kopi sehingga lebih mengedukasi konsumen. Peningkatan gaya produk pada Lestari Coffee Roasters sudah diterapkan Lestari Coffee Roasters yaitu Lestari Coffee Roasters menggunakan cap dalam melabeli kemasan sehingga kemasan terlihat unik.

\section{SIMPULAN}

Alternatif strategi pemasaran yang disarankan untuk meningkatkan penjualan biji kopi panggang pada Lestari Coffee Roasters berdasarkan prioritas bauran orang dengan dimensi pelatihan dan pengembangan yaitu strategi pengembangan produk. Peningkatan kualitas produk dapat dilakukan dengan pelatihan dan pengambangan (sumber daya manusia). Teknis yang dapat dilakukan yaitu bisa dengan menciptakan produk kopi yang siap minum, sehingga lebih praktis.

Berdasarkan prioritas tujuan Melestarikan Budaya Ngopi, bauran orang, dan dimensi pelatihan dan pengembangan, Lestari Coffee Roasters disarankan untuk menggunakan alternatif strategi pengembangan produk. Strategi pengembangan 
Anjani, et.al., Prioritas Strategi Pemasaran Biji Kopi Panggang Menggunakan...

produk dapat dilakukan dengan cara peningkatan kualitas produk, peningkatan keistimewaan produk, dan peningkatan gaya produk. Peningkatan kualitas produk dapat dilakukan dengan pelatihan dan pengembangan. Karena apabila sumberdaya manusia pada Lestari Coffee Roasters memiliki kemampuan dan keterampilan yang baik maka produk yang dihasilkan juga akan berkualitas baik. Teknis yang dapat dilakukan yaitu dengan menciptakan produk siap minum, sehingga membuat praktis konsumen.

\section{DAFTAR PUSTAKA}

Affandy, Mohammad Rizki. 2017. Perencanaan Strategi Pemasaran Perhiasan Imitasi Dengan Metode Analisis SWOT dan Analytical Hierarchy Process (Studi Kasus: UD. Aqila). Jurnal MATRIK, 18 (1), 61-70.

Amelinda, Clara Sugianto dan Charly Hongdiyanto. 2017. Perumusan Strategi Pemasaran Menggunakan Metode QSPM Pada Bisnis Sambal Noesantara. Jurnal Manajemen dan Start-Up Bisnis, 2 (1), 106-115.

Bogdan dan Biklen. 1982. Ciri-ciri Penelitian Kualitatif. Bandung : Fitkom Unpad.

David, R. Fred. 2011. Strategic Management (Manajemen Strategi). Jakarta: Salemba Empat.

Effendi Usman, Retno Astuti, Diana Candra Melati. 2017. Stratgi Pengembangan Usaha Coklat Menggunakan Quantitative Strategic Planning Matrix (QSPM) dan Multi Attribute Theory (MAUT). Jurnal Teknologi dan Manajemen Agroindustri, 6 (1), 31-40.

Hasbi, Rizkiyah Andi. 2018. Penentuan Prioritas Strategi Pemasaran Kopi Arabika (Coffee Arabica) di Kabupaten Bantaeng Dengan Metode AHP (Analytical Hierarchy Process). Jurnal Manajemen, 4 (1), 24-30.

Kotler, P. 1987. Marketing (Terjemahan: Herujati Purwoko). Surabaya: Erlangga.

Mahfud, Tuatul dan Yogiana Mulyani. Aplikasi Merode QSPM (Quantitaive Strategic Planning Matrix) (Studi Kasus: Strategi Peningkatan Mutu Lulusan Program Studi Tata Boga. Jurnal Sosial Humaniora dan Pendidikan, 1 (1), 66-76.

Nurhasanah, Nunung. 2006. Perumusan Strategi Pemasaran Melalui Penentuan Prioritas Trapezoidal Fuzzy Number (Studi Kasus Industri Minuman Tradisional). Jurnal Teknik Industri, 8 (2), 131-140. 
Jurnal Dinamika Sosial Ekonomi, 22 (1) : 17-32

Saaty, T.L. 1993. Pengambilan Keputusan Bagi Para Pemimpin. Jakarta: PT. Pustaka Binaman Pressindo.

Sugiyono. 2019. Metode Penelitian Kuantitatif Kualitatif dan R\&D. Editor: Sutopo. Bandung: Alfabeta Tersina.

Walangare Daniel, Rosa Delima, Restyandito. 2012. Sistem Prediksi Pertandingan Sepak Bola dengan Metode Analytical Hierarchy Process (AHP). Jurnal Teknik Informatika, 8 (2), 181-188.

Zarzoso IM, Lehman FN. 2003. Augmented Gravity Model: An Empirical Application to Mercosur-European Union Trade Flows. Journal of Applied Economics ,6 (2), 291-316.

Setyorini Hany, Mas'ud Effendi, Imam Santoso. 2016. Analisis Strategi Pemasaran Menggunakan Matriks SWOT dan QSMP (Studi Kasus: Restoran WS Soekarno Hatta Malang). Jurnal Teknologi dan Manajemen Agroindustri, 5 (1), 46-53.

Sudjarmoko, Bedy. 2013. Prospek Pengembangan Industrialisasi Kopi Indonesia. SIRINOV, 1 (3), 99-110.

Umar, Husein. 2004. Metode Penelitian Untuk Skripsi Dan Tesis Bisnis. Cetakan ke-6. Jakarta: PT Raja Grafindo Persada. 